Michiko Makino • Satoshi Horai • Yu-ichi Goto

Ikuya Nonaka

\title{
Mitochondrial DNA mutations in Leigh syndrome and their phylogenetic implications
}

\begin{abstract}
Of 100 patients with the clinical diagnosis of Leigh syndrome, 21 were found to have specific enzyme defects: 15 involving cytochrome $c$ oxidase (COX); 4, pyruvate dehydrogenase complex (PDHC); one, complex I (reduced nicotinamide adenine dinucleotide [NADH]-coenzyme $\mathrm{Q}$ reductase) and one, complex II (succinate-ubiquinone reductase) deficiencies. In addition to the most common form of COX deficiency, mtDNA mutations in the adenosine triphosphatase (ATPase) 6 coding region were also commonly seen. Eighteen patients $(18 \%)$ had mtDNA mutations at nucleotide position (np) 8993 or 9176 . The mutated DNAs were present in a heteroplasmic state, comprising more than $90 \%$ of the DNA in muscle and/or blood samples from all patients. Patients with the T-to-G mutation at np 8993 usually had early onset of the disease with rapid progression, showing the typical clinical features of Leigh syndrome. On the other hand, those with the T-to-C 8993 mutation showed a milder and more chronic course. Patients with the mutation at np 9176 showed variable courses. Phylogenetic analysis of mtDNA D-loop sequences for the patients with the ATPase 6 mutations and normal Japanese subjects revealed that a T-to-G/C mutation at np 8993 and a T-to-C mutation at np 9176 occurred many times independently in the Japanese population.
\end{abstract}

Key words Leigh $\cdot$ Mitochondria $\cdot$ ATPase $\cdot$ Phylogeny

M. Makino $(\bowtie) \cdot$ I. Nonaka

Department of Ultrastructural Research, National Institute of

Neuroscience, NCNP, 4-1-1 Ogawahigashi, Kodaira, Tokyo 187-8502, Japan

Tel. +81-42-346-1719; Fax +81-42-346-1749

e-mail:makino@ncnp.go.jp

Y. Goto

Department of Mental Retardation and Birth Defect Research,

National Institute of Neuroscience, NCNP, Tokyo, Japan

S. Horai

Department of Biosystems Science, The Graduate University for

Advanced Studies, Kanagawa, Japan

\section{Introduction}

Leigh syndrome is a neurodegenerative disorder defined neuropathologically by striking bilateral necrotic lesions in the basal ganglia and brainstem (Leigh 1951). As such lesions can now be well demonstrated by brain magnetic resonance imaging (MRI) and computed tomography (CT), the syndrome is no longer diagnosed by its pathology in autopsy specimens. The syndrome can now be diagnosed during life by neuroimaging and by the clinical characteristics of progressive neurologic deficits, and high lactate levels in blood and cerebrospinal fluid (CSF). The syndrome has heterogeneous causes, as a variety of enzyme defects have been reported, including cytochrome $c$ oxidase (COX, complex IV) (Willems et al. 1977) and complex I (reduced nicotinamide adenine dinucleotide [NADH]-coenzyme $\mathrm{Q}$ reductase)(Fujii et al. 1990), and pyruvate dehydrogenase complex (PDHC) deficiencies (De Vivo et al. 1979). In addition, T-to-G and T-to-C mitochondrial (mt) DNA point mutations at nucleotide position (np) 8993 have been shown to be causes of the syndrome (Tatuch et al. 1992; Sakuta et al. 1992; De Vries et al. 1993; Santorelli et al. 1993; Santorelli et al. 1994). Moreover, it has been confirmed that a T-to-C transition at np 9176 is also a mutation responsible for the disease (Thyagarajan et al. 1995; Campos et al. 1997; Dionisi-Vici et al. 1998; Makino et al. 1998).

Mitochondrial ATP synthase (complex V) comprises more than 10 subunits encoded by nuclear DNA and 2 subunits (adenosine triphosphatase [ATPase] 6 and ATPase 8) encoded by mtDNA. Nucleotides from 8527 to 9207 encode the ATPase 6 subunit in which the mutations in this study are located. Two other point mutations have been described in Leigh syndrome; an A-to-G mutation at $\mathrm{np}$ 8344 (Silvestri et al. 1993) and an A-to-G mutation at np 3243 (Shoffner and Wallace 1995), which were initi-ally described in other specific phenotypes of MERRF (myoclonic epilepsy with ragged-red fibers) (Shoffner et al. 1990) and MELAS (mitochondrial myopathy, encephalopathy, lactic acidosis, and stroke-like episodes) (Goto et al. 1990), respectively. 
In this study, we reviewed a large number of patients with Leigh syndrome to clarify the incidence of mtDNA mutations and to characterize the clinical features and muscle pathology. In addition, to determine whether these mutations were transmitted in maternal lineage or occurred sporadically, we examined the mtDNA sequence variation in the D-loop region in the patients who had mtDNA mutations in the ATPase 6 coding region.

\section{Patients and methods}

In this study, we selected 100 patients who had adequate clinical and neuroimaging findings for the diagnosis of Leigh syndrome; progressive neurologic deficits including mental deterioration, hypotonia, convulsions, symmetrical necrotic lesions in the basal ganglia and brainstem on MRI and/or CT, and raised lactate and pyruvate levels in blood and cerebrospinal fluid (CSF). The muscle biopsies and/or blood samples with clinical summaries were referred to our department for pathologic, biochemical, and molecular genetic evaluation during a 20-year period (1978-1997). All the patients were Japanese.

Histochemical and biochemical analyses of muscle specimens were performed on 97 samples. Only blood samples were available from 3 patients. Serial frozen sections were stained with hematoxylin and eosin, modified Gomori trichrome, and various histochemical methods, including succinate dehydrogenase $(\mathrm{SDH})$ and $\mathrm{COX}$. Biochemical analysis of respiratory chain enzymes, including NADH cytochrome $c$ reductase, succinate cytochrome $c$ reductase, COX, and PDHC was performed (Toshima et al. 1985; Koga et al. 1988).

Total DNA was extracted from muscle biopsies and/or blood samples by conventional methods. We first screened well known point mutations in mtDNA at np 3243, 3271, and 8344. Point mutations in the ATPase 6 coding region, including T-to-G and T-to-C at 8993, and T-to-C at 9176, were determined as follows. To detect the T-to-G/C mutation at np 8993 of the mtDNA, we amplified 180-bp fragments, using oligonucleotide primers corresponding to mtDNA positions $\left(5^{\prime}-3^{\prime}\right) 8838-8857$ and $8998-9017$, in 30 cycles of denaturation $\left(94^{\circ} \mathrm{C}, 15 \mathrm{~s}\right)$, annealing $\left(55^{\circ} \mathrm{C}, 15 \mathrm{~s}\right)$, and extension $\left(72^{\circ} \mathrm{C}, 30 \mathrm{~s}\right)$. The PCR products were digested with HpaII and SmaI. When the T-to-G mutation was found, the products were cleaved by both HpaII and SmaI. On the other hand, in the T-to-C mutation, the products were cleaved only by HpaII. To detect the T-to-C mutation at np 9176 we amplified 203-bp fragments, using primers corresponding to mtDNA positions $\left(5^{\prime}-3^{\prime}\right)$ 9001-9020 and 9203-9177 with a T-to-C mismatch at np 9179, in 25 cycles of denaturation $\left(94^{\circ} \mathrm{C}, 15 \mathrm{~s}\right)$, annealing $\left(60^{\circ} \mathrm{C}, 15 \mathrm{~s}\right)$, and extension $\left(72^{\circ} \mathrm{C}, 30 \mathrm{~s}\right)$. The products were digested with ScrfI. Because the mismatch-containing primer introduces a restriction site for ScrfI at 9176 in the mutant mtDNA, mutant mtDNA was cleaved into two fragments of 176 and $27 \mathrm{bp}$. To quantify the proportion of the np 8993 and np 9176 mutant mitochondrial DNA, we added rhodamine-labeled forward primer only in the last cycle. The products were electrophoresed through $15 \%$ acrylamide gel and analyzed with an image analyzer (FMBIO II; Hitachi and Takara Shuzo, Tokyo, Japan).

The nucleotide sequences of a 737-bp fragment of the Dloop region (positions 16024-16569 followed by positions 1 191 in the reference sequence (Anderson et al. 1981)) from 18 Leigh syndrome patients with mutations in mitochondrial ATPase 6 region were aligned and compared. Also, the nucleotide sequences of a 482-bp fragment of the Dloop region (positions 16129-16569 followed by positions 141 in the reference sequence (Anderson et al. 1981)) from the Leigh subjects together with 62 normal subjects (Horai and Hayasaka 1990) were aligned and compared. The number of nucleotide substitutions per site between individual sequences was estimated using the two-parameter model of nucleotide substitutions (Kimura 1980). On the basis of the estimated number of nucleotide substitutions, phylogenetic trees were constructed, using the neighbor-joining (NJ) method (Saitou and Nei 1987) and unweighted pair-group method with arithmetic mean (UPGMA)(Nei 1987).

\section{Results}

In this study the most common enzyme deficiency was COX deficiency, which was found in 15 patients, confirmed by both histochemical and biochemical analyses. Biochemically, we detected PDHC deficiency in 4 patients, complex I deficiency in 1 patient, and complex II deficiency in 1 patient. By molecular genetic analysis, 10 patients had T-to-G and 3 had T-to-C mutations at np 8993, and 5 had a T-to-C mutation at np 9176. Biochemical and molecular defects were identified in 39 of 100 patients (39\%), none of whom was related to each other.

In the ten patients with the T-to-G 8993 mutation, the overall clinical symptoms were similar to those of classical infantile Leigh syndrome. They had early onset of the disease (onset from neonate to 10 months of age; average, 3.9 months), with rapid deterioration. Hypotonia, seizures, respiratory disturbance, and lethargy were found in most of the patients with this mutation. Three of the ten patients died in early infancy. On the other hand, all three patients with the T-to-C 8993 mutation showed milder and more chronic progression.

In the five patients with the T-to-C mutation at np 9176 , the age at onset of the disease varied widely, from 5 months to 8 years. Retinitis pigmentosa was found in five patients; two patients with the T-to-G 8993 mutation, one with the Tto-C 8993 mutation, and two with the T-to-C 9176 mutation. The clinical findings of the patients with mtDNA mutations are summarized in Fig. 1. Three of the patients with the 9176 mutation (T9176C-1, T9176C-2, and T9176C-3) have been previously reported (Makino et al. 1998).

We examined muscle biopsies from 15 of 18 patients with mitochondrial DNA mutations, including 9 of 10 patients with the T-to-G 8993 mutation, 1 of 3 patients with the T-toC 8993 mutation, and all 5 patients with the T-to-C 9176 


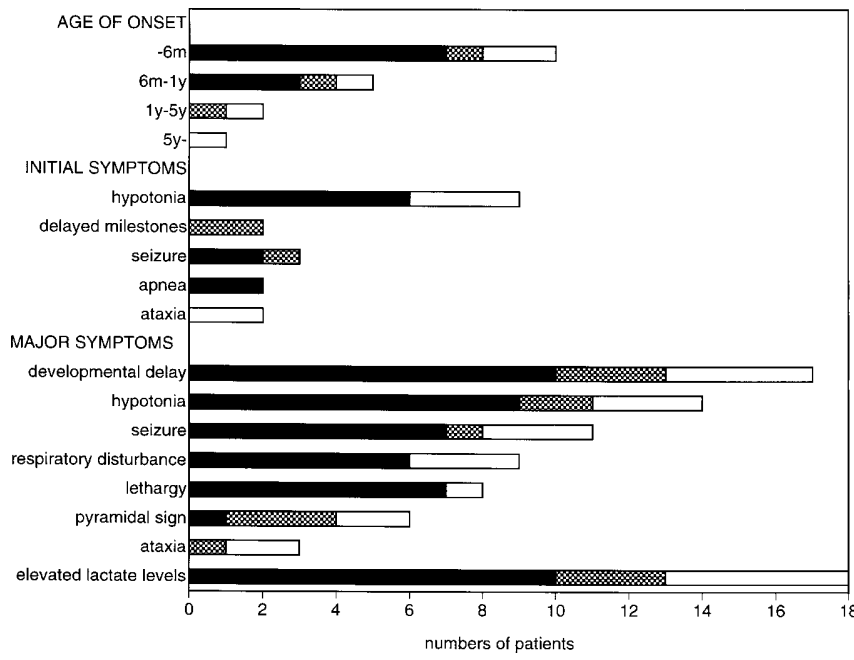

Fig. 1. Clinical summary of patients with mitochondrial (mt)DNA mutations. Black bars, T8993G $(n=10)$; stippled bars, T8993C $(n=3)$; open bars, T9176C $(n=5)$

mutation. Muscle pathologic findings are summarized in Fig. 2. On muscle histochemistry, there were nonspecific myopathic changes with mild-to-moderate variation in the size of both type 1 and 2 fibers, with type $2 \mathrm{~B}$ fiber atrophy and increased numbers of type $2 \mathrm{C}$ fibers. In 2 patients there were additional mild neuropathic changes with scattered small angular fibers and mild fiber type grouping. None of the 15 patients had ragged-red fibers, but 1 patient with the T-to-G 8993 mutation had large dark stained granules on SDH staining. Mitochondria were enlarged, with focal myofibrillar degeneration on electron microscopy (Fig. 3).

The activities of mitochondrial respiratory chain enzymes were within normal limits, except in two patients with the T-to-G 8993 mutation. NADH cytchrome $C$ reductase (NCCR) and COX activities were reduced to $40 \%$ in one patient, and COX activity was decreased to $25 \%$ in another.

The proportion of mutant DNA constituted more than $90 \%(91 \%$ to $>99 \%)$ of the DNA in muscle and/or blood samples of all the patients. We examined the proportion of the mutant DNA in various tissues taken at necropsy from a patient with the T-to-G 8993 mutation. Heart, liver, kidney, pancreas, lung, spleen, cerebrum, cerebellum, brainstem, aorta, and spinal cord all showed similarly high proportions of mutants $(97 \%$ to $>99 \%)$. We obtained blood from the asymptomatic mothers of nine patients, including the mothers of seven patients with the T-to-G 8993 mutation, one patient with the T-to-C 8993 mutation, and one patient with the T-to-C 9176 mutation. Seven of the mothers had $20 \%-52 \%$ of mutated DNA, but no mutant genome was found in the mothers of two of the patients with the T-to-G 8993 mutation (Fig. 4).

The nucleotide sequences (717-bp) of the D-loop region were variable, and no common sequences were found in the 18 patients. Phylogenetic analysis revealed that ten lineages with the T8993G mutation and three lineages with the T8993C mutation were intermingled in the phylogenetic tree (Fig. 5). Although three lineages with the T9176C mutation formed a cluster, two other lineages appeared at

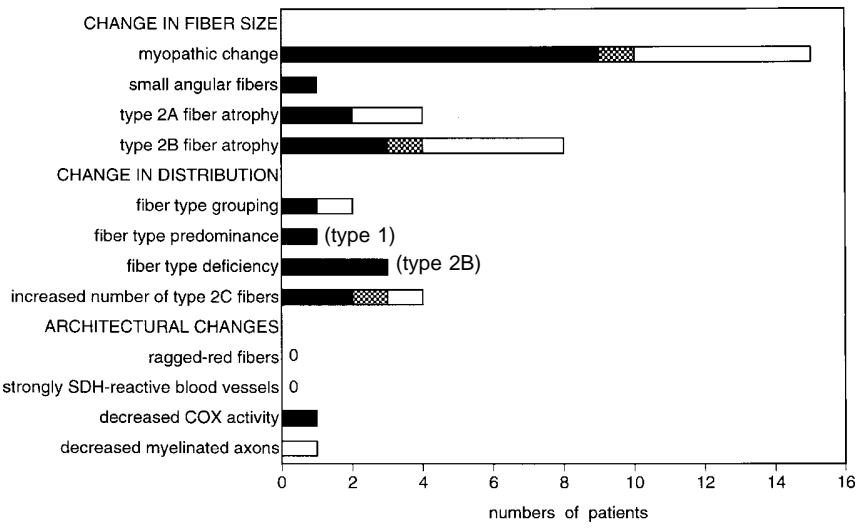

Fig. 2. Muscle pathology. $S D H$, Succinate dehydrogenase; $C O X$, cytochrome $c$ oxidase. Black bars, T8993G $(n=9)$; stippled bars, T8993C $(n$ $=1)$; open bars, $\mathrm{T} 9176 \mathrm{C}(n=5)$

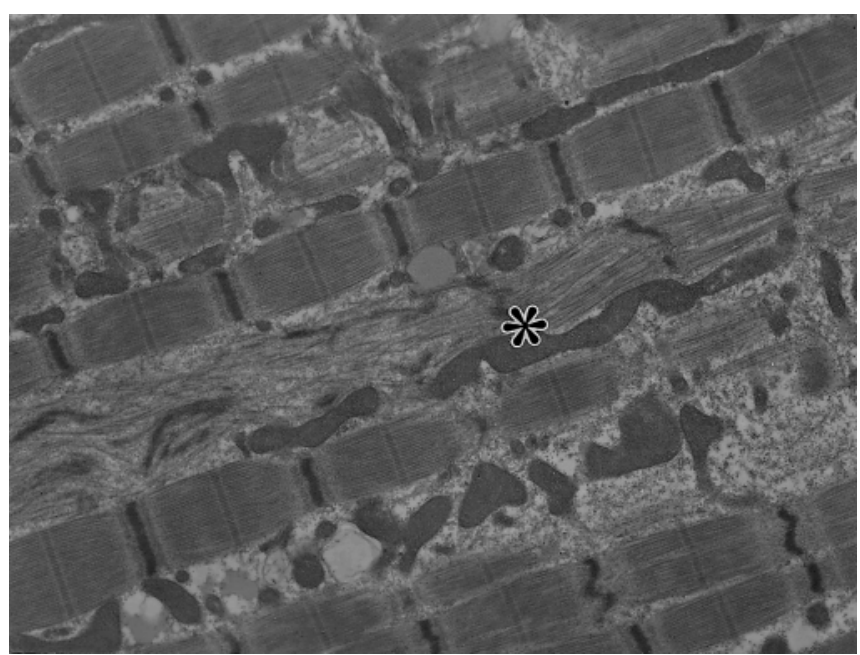

Fig. 3. Electron micrograph of muscle from a patient with 8993 T-to-G mutation (T8993G-1). Note enlarged mitochondria with disorganized myofibrils (asterisk). No paracrystalline inclusions are present. $\times 8000$

different locations in the tree. These results suggest that common pathogenicity (Leigh syndrome with ATPase 6 mutations) occurs sporadically in lineages which have different maternal backgrounds. These independent occurrences of ATPase 6 mutations in the patients were also evident when phylogenetic analysis of the D-loop region was performed for the patients together with normal control subjects. In order to determine the location of each of the 18 patients in the phylogenetic tree, the 482-bp sequences of the D-loop sequences were compared with those of 62 normal Japanese (Fig. 6). Although two patient lineages (T8993G-5 and T8993G-6) formed a tight cluster, most of the other patient lineages were interspersed with those of normal individuals and were scattered in the phylogenetic tree. 
Fig. 4. Proportion of mutated genome in muscle (black bars) and blood (stippled bars) samples. Almost all muscle and blood samples from patients with Leigh syndrome had a very high proportion of mutant genomes. Two (T8993G-2 and T8993G-9) of nine blood samples from the mothers had no detectable mutant genomes, this being suggestive of denovo mutation. Cross-hatched bars, Blood of mother. ne, Not examined

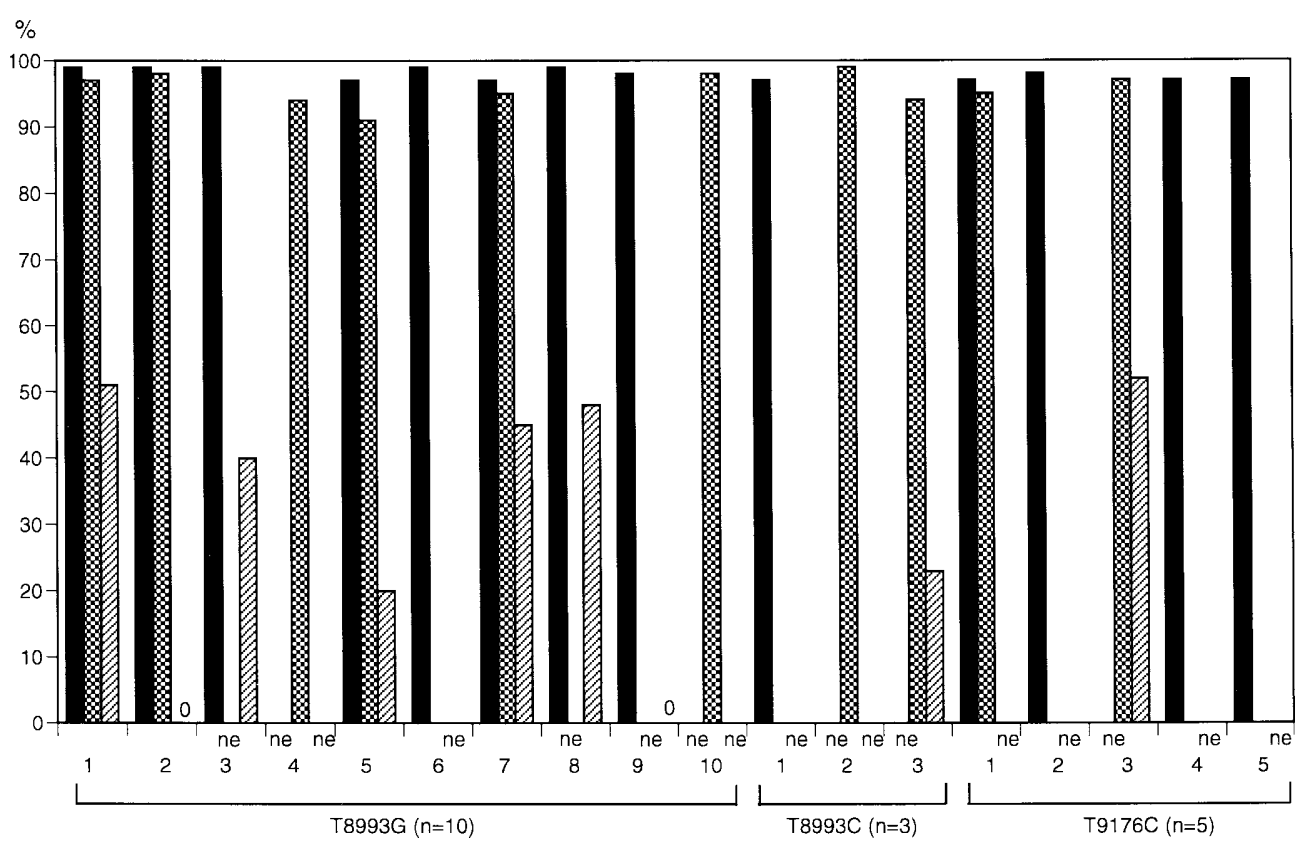

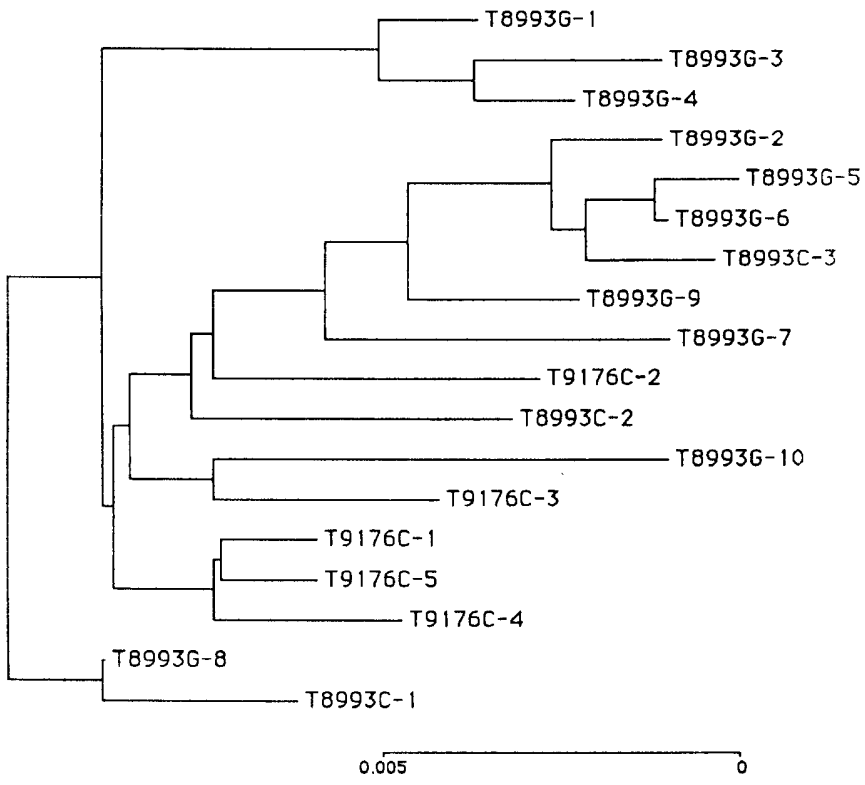

Fig. 5. Neighbor-joining tree, showing the relationship of the 18 patient lineages with the ATPase 6 mutations, based on the number of nucleotide substitutions per site

\section{Discussion}

Leigh syndrome is a group of heterogeneous disorders, including deficiencies of COX, complex I and PDHC, and mtDNA mutations. We identified biochemical or molecular defects in $39 \%$ (39 of 100) of Leigh syndrome patients in this study, that is, in approximately $60 \%$ of patients we were unable to find the etiological defect(s). Nevertheless, there was no difference in the clinical features and pathologic findings in these two groups. As mutations of $S U R F-1$ have recently been identified in patients affected by Leigh syn- drome with cytochrome $c$ oxidase deficiency (Zhu et al. 1998; Tiranti et al. 1998; Tiranti et al. 1999), we have examined the gene in 14 patients and found that 4 had the mutation (unpublished data).

The most striking finding in this study was the higher incidence of mtDNA mutations in the ATPase 6 coding region. Eighteen percent (18 of 100) of our patients had mtDNA mutations, 10 with the T-to-G 8993 mutation, 3 with the T-to-C 8993 mutation, and 5 with the T-to-C 9176 mutation. In the literature, there are three reports describing the incidence of mtDNA mutations in Leigh syndrome: 12 of 50 patients who had no biochemical defects had the T-to-G 8993 mutation (Santorelli et al. 1993); of 11 of 67 patients with mtDNA mutations, 6 had the T-to-G 8993 mutation, 1 had the T-to-C 8993 mutation, and 1 had the A-to-G 8344 mutation (Rahman et al. 1996); and of 3 of 66 patients with mtDNA mutations, 2 had the T-to-G 8993 mutation, and 1 had the A-to-G 8344 mutation (Morris et al. 1996). Together with our findings, the overall incidence of the 8993 mutation in Leigh syndrome seems to be the most common cause of the disease, accounting for $15 \%-20 \%$ of the patients.

The clinical features of Leigh syndrome with the mtDNA mutations are not specific, showing the common features of developmental delay, muscle hypotonia, and seizures. The only minor differences clinically among the three mtDNA mutations were in the age of onset and the course of the disease. As previously reported, the onset in patients with the T-to-G 8993 mutation was earlier, with rapid mental deterioration, seizures, and respiratory problems. Those with the T-to-C 8993 mutation showed slower progression compared with those with the T-to-G 8993 mutation (De Vries et al. 1993; Santorelli et al. 1994; Rahman et al. 1996). Recent reports have confirmed that the T-to-C 9176 mutation in the ATPase 6 coding region is also a candidate mutation for Leigh syndrome. Two Jewish brothers with bilateral striatal necrosis, which mimics Leigh 
Fig. 6. Unweighted pair-group method with arithmetic mean (UPGMA) phylogenetic tree showing the 18 patients and 62 normal Japanese subjects, based on the number of nucleotide substitutions per site. Patient lineages with the ATPase 6 mutations are indicated by arrows

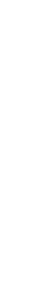

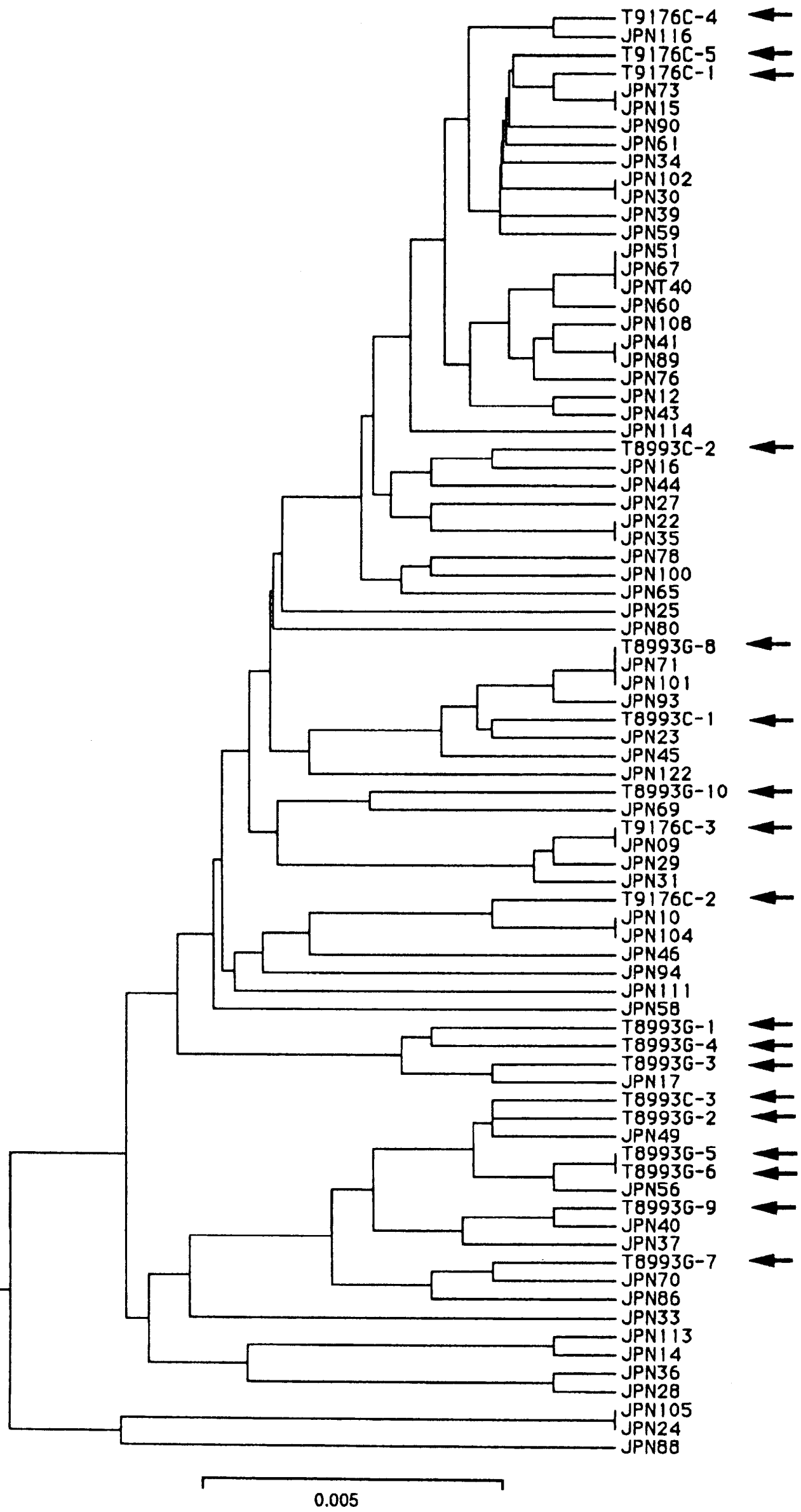


syndrome (Thyagarajan et al. 1995), one Spanish patient (Campos et al. 1997) and three Japanese patients (Makino et al. 1998) with Leigh syndrome, and an Italian family with fulminant Leigh syndrome and sudden unexpected death (Dionisi-Vici et al. 1998) have been reported.

The muscle changes were not mutation-specific, but similar to those seen in a previous study of patients with Leigh syndrome (Nagai et al. 1992). There were nonspecific myopathic changes with little or no abnormal mitochondrial pathology. This is distinctly different from the changes seen in patients with mitochondrial tRNA mutations.

In all patients the proportion of the mutant DNA was over $90 \%$ ( $91 \%$ to $>99 \%$ ) in muscle and blood samples, as in the patients previously reported (Tatuch et al. 1992; Santorelli et al. 1993; Uziel et al. 1997). The threshold level of the mutant mtDNA necessary to produce neurological deficits in Leigh syndrome appears to be $90 \%$. Except for large-scale deletions, mtDNA mutations are inherited through a maternal trait. Seven of nine mothers of our patients had $20 \%-52 \%$ of the mutant DNA in blood samples, but no detectable mutant genome was found in two mothers with the T-to-G 8993 mutation. These findings suggest that de-novo mutations occur during oogenesis, or that the distribution of the mutant is skewed in the oocytes of the mother. There are some reports that mothers and/or grandmothers of patients with the T-to-G 8993 mutation had no mutant DNA in the blood (Tulinius et al. 1995; Blok et al. 1997; Uziel et al. 1997; Takahashi et al. 1998).

Our study of D-loop sequences in the patients supports the possibility of new mutations. The D-loop region of mtDNA is more rapidly evolved than other parts and is more variable, so that the D-loop region has been used as an evolutionary marker (Horai and Hayasaka 1990; Horai et al. 1991). Phylogenetic analysis of the D-loop region suggests that common pathogenicity (Leigh syndrome with ATPase 6 mutations) occurs sporadically in lineages which have different maternal backgrounds. This phylogenetic analysis indicates that there was no common ancestor for the patients bearing either of the ATPase 6 mutations, and that these mutations occurred sporadically and multiplied through the mtDNA evolution in Japan. Similar findings, based on the variability of nucleotides in the D-loop, have been reported for the A-to-G 3243 mutation (Morten et al. 1995), for mtDNA mutations associated with Leber hereditary optic neuropathy (LHON) (Brown et al. 1995; Howell et al. 1995), and for the A-to-G 1555 mutation in deafness (Hutchin and Cortopassi 1997). Two recent reports noted clustering in Caucasian LHON patients with 11778 and 14484 mutations (Brown et al. 1997; Torroni et al. 1997).

In conclusion, mtDNA analysis should be considered for the diagnosis of Leigh syndrome, on the bases of the relatively high frequency of mtDNA mutations and the paucity of information available from muscle biopsy samples.

Acknowledgments We would like to thank all the families and clinicians whose participation made this study possible. We are grateful to Dr. S.M. Sumi, Department of Pathology, University of Washington, for his kind advice and suggestions. This research was supported in part by the grants from the Ministry of Health and Welfare and from the Science and Technology of Japan.

\section{References}

Anderson S, Bankier AT, Barrell BG, De Brujin MHL, Coulson AR, Drouin J, Eperon IC, Nierlich DP, Roe BA, Sanger F, Schreier PH, Smith AJH, Staden R, Young IG (1981) Sequence and organization of the human mitochondrial genome. Nature 290:457-465

Blok RB, Gook DA, Thorburn DR, Dahl HHM (1997) Skewed segregation of the mtDNA nt 8993 ( $T$ to $G$ ) mutation in human oocytes. Am J Hum Genet 60:1495-1501

Brown MD, Trroni A, Reckord CL, Wallace DC (1995) Phylogenetic analysis of Leber's hereditary optic neuropathy mitochondrial DNAs indicates multiple independent occurrences of the common mutations. Hum Mutat 6:311-325

Brown MD, Sun F, Wallace DC (1997) Clustering of Caucasian Leber hereditary optic neuropathy patients containing the 11778 or 14484 mutations on an mtDNA lineage. Am J Hum Genet 60:381-387

Campos Y, Martin MA, Rubio JC, Solana LG, García-Benayas C, Terradas JL, Arenas J (1997) Leigh syndrome associated with the T9176C mutation in the ATPase 6 gene of mitochondrial DNA. Neurology 49:595-597

De Vivo DC, Haymond MW, Obert KA, Nelson JS, Pagliara AS (1979) Defective activation of the pyruvate dehydrogenase complex in subacute necrotizing encephalomyelopathy (Leigh disease). Ann Neurol 6:483-494

De Vries DD, van Engelen BGM, Gabreëls FJM, Ruitenbeek W, van Oost BA (1993) A second missence nutation in the mitochondrial ATPase 6 gene in Leigh's syndrome. Ann Neurol 34:410-412

Dionisi-Vici C, Seneca S, Zeviani M, Fariello G, Rimoldi M, Bertini E, de Meirleir L (1998) Fulminant Leigh syndrome and sudden unexpected death in family with the T9176C mutation of the mitochondrial ATPase 6 gene. J Inherit Metab Dis 21:2-8

Fujii T, Ito M, Okuno T, Mutoh K, Nishikomori R, Mikawa H (1990) Complex I (reduced nicotinamide-adenine dinucleotide-coenzyme $\mathrm{Q}$ reductase) deficiency in two patients with probable Leigh syndrome. J Pediatr 116:84-87

Goto Y, Nonaka I, Horai S (1990) A mutation in the tRNA(Leu)(UUR) gene associated with the MELAS subgroup of mitochondrial encephalomyopathies. Nature 348:651-653

Holt IJ, Harding AE, Petty RKH, Morgan-Hughes JA (1990) A new mitochondrial disease associated with mitochondrial DNA heteroplasmy. Am J Hum Genet 46:428-433

Horai S, Hayasaka K (1990) Intraspecific nucleotide sequence differences in the major noncoding region of human mitochondrial DNA. Am J Hum Genet 46:828-842

Horai S, Kondo R, Murayama K, Hayashi S, Koike H, Nakai N (1991) Phylogetic affiliation of ancient and contemporary humans inferred from mitochondrial DNA. Phil Trans R Soc Lond B 333:409-417

Howell N, Kubacka I, Halvorrson S, Howell B, McCullough DA, Mackey D (1995) Phylogenetic analysis of the mitochondrial genomes from Leber hereditary optic neuropathy pedigrees. Genetics 140:285-302

Hutchin TP, Cortopassi GA (1997) Multiple origins of a mitochondrial mutation conferring deafness. Genetics 145:771-776

Kimura M (1980) A simple method for estimating evolutionary rate of base substitutions through comparative studies of nucleotide sequences. J Mol Evol 16:112-120

Koga Y, Nonaka I, Sunohara N, Yamanaka R, Kumagai K (1988) Variability in the activity of respiratory chain enzymes in mitochondrial myopathies. Acta Neuropathol 76:135-141

Leigh D (1951) Subacute necrotizing encephalomyelopathy in an infant. J Neurol Neurosurg Psychiatry 14:216-221

Makino M, Horai S, Goto Y, Nonaka I (1998) Confirmation that a Tto-C mutation at 9176 in mitochondrial DNA is an additional candidate for Leigh's syndrome. Neuromuscul Disord 8:149-151

Morris AAM, Leonard JV, Brown GK, Bidouki SK, Bindoff LA, Woodward CE, Harding AE, Lake BD, Harding BN, Farrell MA, Bell JE, Mirakhur M, Turnbull DM (1996) Deficiency of respiratory chain complex I is a common cause of Leigh disease. Ann Neurol 40:25-30

Morten KJ, Poulton J, Sykes B (1995) Multiple independent occurrence of the 3243 mutation in mitochondrial tRNA ${ }^{\text {leuUUR }}$ in patients with the MELAS phenotype. Hum Mol Genet 4:1689-1691

Nagai T, Goto Y, Matsuoka T, Sakuta R, Naito E, Kuroda Y, Nonaka 
I (1992) Leigh Encephalopathy: histologic and biochemical analyses of muscle biopsies. Pediatr Neurol 8:328-332

Nei M (1987) Molecular evolutionary genetics. Columbia University Press, New York, pp 293-298

Rahman S, Blok RB, Dahl H-HM, Danks DM, Kirby DM, Chow CW, Christodoulou J, Thorburn DR (1996) Leigh syndrome: clinical features and biochemical and DNA abnormalities. Ann Neurol 39:343351

Saitou N, Nei M (1987) The neighbor-joining method: a new method for contructing phylogenetic trees. Mol Biol Evol 4:406-425

Sakuta R, Goto Y, Horai S, Ogino T, Yoshinaga H, Ohtahara S, Nonaka I (1992) Mitochondrial DNA mutation and Leigh's syndrome. Ann Neurol 32:597-598

Santorelli FM, Shanske S, Macaya A, De Vivo DC, DiMauro S (1993) The mutation at nt 8993 of mitochondrial DNA is a common cause of Leigh's syndrome. Ann Neurol 34:827-834

Santorelli FM, Shanske S, Jain KD, Tick D, Schon EA, Dimauro S (1994) A T-to-C mutation at nt 8993 of mitochondrial DNA in a child with Leigh syndrome. Neurology 44:972-974

Shoffner JM, Lott MT, Lezza AM, Seibel P, Ballinger SW, Wallace DC (1990) Myoclonic epilepsy and ragged-red fiber disease (MERRF) is associated with a mitochondrial DNA tRNA(Lys)

Shoffner JM, Wallace DC (1995) Oxidative phosphorylation diseases. In: Scriver CR, Beaudet AL, Sly WS, Valle MD (eds) The metabolic and molecular bases of inherited disease, 7 th edn. McGraw Hill, New York, pp1535-1609

Silvestri G, Ciafaloni E, Santorelli FM, Shanske S, Servidei S, Graf WD, Sumi M, DiMauro S (1993) Clinical features associated with the A-to-G transition at nucleotide 8344 of mtDNA ("MERRF mutation”). Neurology 43:1200-1206

Takahashi S, Makita Y, Oki J, Miyamoto A, Yanagawa J, Naito E, Goto Y (1998) De novo mtDNA nt $8993(\mathrm{~T} \rightarrow \mathrm{G})$ mutation resulting in Leigh syndrome. Am J Hum Genet 62:717-719

Tatuch Y, Christodoulou J, Feigenbaum A, Clarke JTR, Wherret J, Smith C, Rudd N, Petrova-Benedict R, Robinson BH (1992) Heteroplasmic mtDNA mutation (T-to-G) at 8993 can cause Leigh disease when the percentage of abnormal mtDNA is high. Am J Hum Genet 50:852-858

Thyagarajan D, Shanske S, Vazquez-Memije M, DeVivo D, Dimauro S (1995) A novel mitochondrial ATPase 6 point mutation in familial bilateral striatal necrosis. Ann Neurol 38:468-472
Tiranti V, Hoertnagel K, Carrozzo R, Galimberti C, Munaro M, Granatiero M, Zelante L, Gasparini P, Marzella R, Rocchi M, Bayona-Bafaluy MP, Enriquez JA, Uziel G, Bertini E, Dionisi-Vici C, Franco B, Meitinger T, Zeviani M (1998) Mutations of SURF-1 in Leigh disease associated with cytochrome $c$ oxidase deficiency. Am J Hum Genet 63:1609-1621

Tiranti V, Jaksch M, Hofmann S, Galimberti C, Hoertnagel K, Lulli L, Freisinger P, Bindoff L, Gerbitz KD, Comi GP, Uziel G, Zeviani M, Meitinger T (1999) Loss-of-function mutations of SURF-1 are specifically associated with Leigh syndrome with cytochrome $c$ oxidase deficiency. Ann Neurol 46:161-1666

Torroni A, Petrozzi M, D'Urbano L, Sellitto D, Zeviani M, Carrara F, Carducci C, Leuzzi V, Carelli V, Barboni P, De Negri A, Scozzari R (1997) Haplotype and phylogenetic analyses suggest that one European-specific mtDNA background plays a role in the expression of Leber hereditary optic neuropathy by increasing the penetrance of the primary mutations 11778 and 14484. Am J Hum Genet 60:11071121

Toshima K, Kuroda Y, Naito E, Yokota Y, Ito M, Watanabe T, Takeda E, Miyao M, Nonaka I (1985) Diagnosis of partial deficiency of the pyruvate dehydrogenase complex in biopsied muscle. Neurology 35:1670-1672

Tulinius MH, Houshmand M, Larsson NG, Holme E, Oldfors A, Holmberg E, Wahlström J (1995) De novo mutation in mitochondrial ATP synthase subunit 6 gene (T8993G) with rapid segregation resulting in a Leigh syndrome in offspring. Hum Genet 96:290-294

Uziel G, Moroni I, Lamantea E, Fratta GM, Ciceri E, Carrara F, Zeviani M (1997) Mitochondrial disease associated with the T8993G mutation of the mitochondrial ATPase 6 gene: a clinical, biochemical, and molecular study in six families. J Neurol Neurosurg Psychiatry 63:16-22

Willems JL, Monnens LA, Trijbels JM, Veerkamp JH, Meyer AE, van Dam K, van Haelst U (1977) Leigh encephalomyelopathy in a patient with cytochrome $c$ oxidase deficiency in muscle tissue. Pediatrics 60:850-857

Zhu Z, Yao J, Johns T, Fu K, De Bie I, Macmillan C, Cuthbert AP, Newbold RF, Wang J, Chevrette M, Brown GK, Brown RM, Shoubridge EA (1998) SURF1, encoding a factor involved in the biogenesis of cytochrome $c$ oxidase, is mutated in Leigh syndrome. Nat Genet 20:337-343 